\title{
Marx y la tradición iusnaturalista en un mundo industrializado
}

\section{Marx and the natural rights tradition in an industrialised world}

\author{
EDGAR MANJARIN CASTELLARNAU*
}

\begin{abstract}
Resumen: La obra de Marx presenta una base normativa congruente con un núcleo de presupuestos procedentes de la tradición iusnaturalista. Esta tradición de origen medieval partió de una revisión de la codificación tardía del derecho romano. La evolución conceptual de derechos naturales subjetivos culminó, en su forma más radical, con el impulso de la movilización popular democrático-fraternal de la Revolución francesa. Para Marx la defensa de los derechos naturales no se correspondía con las condiciones objetivas a las que daba lugar el proceso de industrialización. Adecuó una tarea teórico-práctica para sintetizar este núcleo normativo en la comprensión de las transformaciones económicas en curso así como en el programa político socialista. Palabras clave: derechos naturales, Karl Marx, industrialización, socialismo
\end{abstract}

\begin{abstract}
Marx's works present a normative ground which is consistent with a core of assumptions originated from the natural rights tradition. This medieval tradition departed from the revision of the late-codification of Roman law. The conceptual evolution of subjective natural rights culminated, in its most radical form, with the momentum of the fraternal-democratic popular movement in the French revolution. For Marx, the defence of natural rights didn't correspond with the objective conditions to which the process of industrialisation gave way. He adapted a theoretical-practical task for synthesising this normative core for the comprehension of the economic transformations underway as well as for a socialist political agenda. Keywords: natural rights, Karl Marx, industrialisation, socialism
\end{abstract}

\section{Superando el desencuentro entre republicanismo, socialismo y iusnaturalismo}

Tras casi dos décadas, el auge académico "neorrepublicano" ha ganado el mérito de recobrar un buen grado de informatividad sobre un marco de conceptos históricos del pensamiento político, logrando rehabilitar el legado de la tradición republicana para discusiones normativas actuales. Este campo ha dado lugar, más recientemente, a importantes revelaciones sobre la ascendencia republicana democrática tanto del propio Karl Marx como de la mayor parte de sus fuentes de inspiración ${ }^{1}$. Estas investigaciones han tenido que afrontar

Recibido: 21/05/2020. Aceptado: 17/06/2020. Cómo citar este articulo: Manjarín, E. (2020). Marx y la tradición iusnaturalista en un mundo industrializado. Daimon. Revista Internacional de Filosofía, (81), 145-160. https:// doi.org/10.6018/daimon.429001

* Universidad de Barcelona (profesor asociado) (edgarmanjarin@ub.edu). Líneas de investigación: Historia del republicanismo; Historia del trabajo asalariado. Trabajo realizado en el marco del proyecto PGC2018-094324B-I00 (MCIU/AERFEDER, UE). Queremos agradecer a Julio Martínez-Cava sus valiosas aportaciones para la redacción de este texto.

1 Las dos aportaciones más destacadas en este ámbito son las de William C. Roberts (2016), Bruno Leipold (2017) y Michael J. Thompson (2019). Todos ellos trazan al detalle datos históricos con el propósito de informar y fundamentar sus desarrollos teóricos. Por otro lado, aunque su investigación viene de antes sin circunscribirse estrictamente en el marco neorrepublicano académico, puede verse en algunas de las principales publicaciones de Antoni Domènech un planteamiento muy cercano. 
retos sustantivos, surgidos de un marco restringido, forjado por influyentes historiadores y filósofos, los propiamente llamados "neorrepublicanos" (siendo los más destacados el historiador Quentin Skinner y el filósofo Philip Pettit). La insuficiente indagación empírica de los procesos sociales que encarnaron el republicanismo clásico, especialmente en el período de consolidación de las polis griegas, a menudo ha vuelto opacas las causas históricas y los contextos por los que la tradición republicana desarrolló conceptos, prácticas e instituciones políticas. Por otro lado, las hondas implicaciones socio-económicas del proceso de industrialización quedaron relegadas a un segundo plano. Al dar prioridad a una discusión sobre la forma de gobierno, todo un conjunto de relaciones económicas quedaba infrateorizado. El mismo Pettit, por ejemplo, no omitió la posibilidad de una "esclavitud salarial", pero los mecanismos causales que exponían a los trabajadores a potenciales inferencias arbitrarias carecían de especificidad (Gourevitch, 2013).

Otra suerte de dificultades se presenta al cotejar los "ecos" republicanos hallados en la obra de Marx con la amplísima variedad interpretativa a la que ha dado lugar su legado. En este artículo trataremos de mostrar cómo Marx ofreció una nueva síntesis, socialista, de los fundamentos filosófico-políticos del republicanismo moderno y la tradición del derecho natural. Para ello será preciso desentrañar en qué sentido dio continuidad al espíritu revolucionario del movimiento de la Montaña en la Revolución Francesa y por qué, tras su derrota, el lenguaje de los derechos naturales se convirtió en un peligroso juego de espejos a la hora de plantear un nuevo sentido de época para la causa fraternal. Marx se sirvió de un esquema normativo impulsado por una evolución del derecho de origen tardofeudal, a la que tanto movimientos populares como pensadores del ala radical de la Ilustración contribuyeron a expandir. Esto le permitió, como veremos más adelante: a) confrontar afirmaciones jurídico-políticas que anticipaban dogmáticamente el devenir histórico; b) revelar las raíces de la dominación de las relaciones de producción en un mundo transformado por la industrialización, y c) habilitar un plano de fundamentación ético-política que trascendía la consecución de derechos civiles y políticos, tratando así de adecuar una comprensión de fuerzas sociales existentes a un principio fiduciario universalmente válido.

\section{La tradición de los derechos naturales}

A partir del siglo XII se originó un movimiento intelectual dispuesto a revisar las fuentes de derecho de un modo que comenzó a desligarse progresivamente de premisas teocráticas. Los juristas revisaron la división tripartita del derecho romano que había quedado cristalizada en el influyente código Justiniano: derecho natural, derecho de gentes y derecho civil ${ }^{2}$. El historiador Brian Tierney dejó un testimonio para la posteridad en su magna obra The Idea of Natural Rights (Tierney, 2001) con una detallada reconstrucción de este proceso, mostrando cómo el pensamiento político moderno hunde sus raíces en una inédita concepción de derechos naturales subjetivos nacida al calor de una renovada vida social en ciudades y comunidades campesinas. La nueva connotación del ius como derecho subjetivo, es decir,

2 Esta división se encuentra en el Código y en el Digesto de Justiniano, que forman parte del Corpus Iuris Civilis (un intento de sistematización tardía del Imperio romano del siglo VI) no en las Instituciones de Gayo, un tercer compendio que cayó en el olvido hasta el siglo XIX. Esta circunstancia es de particular interés para seguir la pista sobre la influencia de su redescubridor, B.G. Niebuhr, a quien Marx leyó y citó profusamente. 
como facultas (poder o fuerza) para determinar lo que es justo, no fue una innovación puramente especulativa. Los juristas de la época se dispusieron a atender los conflictos sociales contemporáneos, de modo que fue "el uso cotidiano" de esa expresión el que "infectó", dice Tierney, "el lenguaje de los canonistas cuando empezaron a escribir sobre el ius naturale" (2001, p. 62). A su vez estos primeros desarrollos arraigaron en nuevas disputas sobre los usos de tierras y recursos naturales dando pie al renacer de la possessio communis, la antigua idea grecorromana sobre la propiedad común originaria. De esta nueva lectura se desprendía que la apropiación privada solo era legítima si se sometía a algún tipo de acuerdo entre seres humanos (Garnsey, 2007).

En el hiato comprendido entre la caída del Imperio romano y la recepción moderna de los canonistas el cristianismo había fagocitado el derecho natural, y con él, toda concepción antropológica que no fuera sometida a la voluntad divina. Así que la moderna invocación al derecho natural vino también acompañada por el renacer de la virtud y la honestidad (honeste vivere en palabras de Ulpiano), un plano de justicia completa que, a diferencia de los dos otros grandes principios regulativos del derecho romano, la justicia correctora y justicia distributiva, se distinguía por el reconocimiento de una capacidad de autoelección moral $^{3}$. Vivir honestamente requeriría, por lo pronto, respetar esa capacidad reflexivamente, con uno mismo, y recíprocamente, con los demás. De este plano de justicia se deduce un principio de no-instrumentalización, puesto que los fines de los agentes solo pueden ser reconocidos como fines en sí mismos ${ }^{4}$. En el ámbito del derecho civil romano ese principio prescribía la radical división entre individuos de derecho propio (sui iuris) e individuos de derecho ajeno (alieni iuris), ya que los segundos no podían gozar de condiciones de existencia autónoma, pues dependían de los primeros. La inalienabilidad de esta condición era, por lo tanto, premisa fundamental del derecho civil, y con arreglo a esta debían instituirse las garantías necesarias para satisfacerla. Esto es, habilitar la libertad política como base constitutiva del derecho.

Pero la consecución de la justicia completa en correspondencia con la justicia distributiva y la justicia correctora suponía un problema que no obtuvo una clara formulación hasta finales del siglo XVIII ${ }^{5}$. Al conjugarse el derecho natural con derechos subjetivos, la sistematización del derecho romano se reveló contradictoria a medida que fue conformándose una orientación más antropocéntrica. Tratar de rescatar ideas de la filosofía clásica suponía todo un rompecabezas, pues si bien la razón emanaba de la naturaleza en la cultura estoica y aristotélica, su esclarecimiento quedaba diluido en una cierta mística por la que el derecho natural "no es propio de los seres humanos, sino común a todos los animales de la tierra y el mar, también es común a las aves" (Ulpiano). Esta facultad, sin embargo, quedaba necesariamente restringida a unos pocos por las instituciones del derecho romano en tanto

3 Poco después de abordar esta cuestión en el libro De la ética a la política (Domènech, 1989), Antoni Domènech publicó un artículo donde ponía en relación el problema de la justicia completa con la obra de Marx (1993).

4 En un trabajo escolar (1835), Marx dejó escrito lo siguiente: "Pero el mérito solo puede asegurarse por una profesión en la que no seamos herramientas serviles, en la cual actuemos independientemente en nuestra propia esfera" (Marx, 1997, 35). En su adolescencia Marx tuvo profesores simpatizantes con el jacobinismo que luego fueron perseguidos por ello; el director de la Escuela, admirador de Kant, escribió para sus alumnos un Manual de instrucción sobre deberes y derechos del hombre y el ciudadano (Stedman Jones, 2017, 136).

5 Ver Bertomeu (2017) sobre los planteamientos de Kant al respecto. 
que excluía a la mayor parte de seres humanos de poder gozar el estatus jurídico de sui iuris. Los preceptos legales romanos sobre las relaciones de dependencia se erigían contra natura. De modo que la naciente rehabilitación del derecho natural sirvió a la causa de los movimientos populares fundamentalmente para promover consignas antiexpropiatorias ${ }^{6}$, pero no traía grandes promesas ante la amenaza de la servidumbre.

Sobre esta senda, y por la fuerza de los hechos, un conjunto de autores de la escolástica tardía del siglo XVI jugó un importante papel transmisor en la tradición de los derechos naturales. Ante las brutales masacres, esclavizaciones masivas y colonización de tierras de los conquistadores españoles, se remitieron a los derechos naturales para denunciar tales hechos como crímenes contra la humanidad. Bartolomé de Las Casas, Francisco de Vitoria y sus seguidores no solo desacreditaron con rotundidad que la esclavitud pudiera derivarse del derecho natural, sino que defendieron el derecho inalienable de los indígenas a gobernarse a sí mismos y a sacar provecho de sus tierras. Las enormes repercusiones de esta controversia llegan a nuestros días por múltiples motivos. Pero lo que nos interesa aquí es que introdujeron un carácter cosmopolita en la comprensión de los derechos naturales. Esta divisa suponía romper las barreras del ius gentium para convertirlo en un plano normativo de afirmación de los derechos de los pueblos. Pero más importante aún: conferían a los derechos naturales un principio universalista que recaía, esta vez, en un sujeto impersonal, la Humanidad, compuesto por todos y cada uno de seres humanos en tanto que miembros del mismo género.

Una tripartición normativa podía comenzar a adoptar así la jerarquización de derechos individuales, derechos de los pueblos y derechos por los que la Humanidad devenía en última instancia beneficiaria (Domènech y Bertomeu, 2016, 14). Las aportaciones de Locke en el período revolucionario inglés dejaron para la posteridad una primera formulación de este esquema bajo un principio fiduciario. Locke recogió de los agravios reportados por los propios movimientos populares una novedosa concepción de la soberanía que le permitió, por un lado, legitimar la movilización popular revolucionaria sobre la base de este principio. No solo una forma de gobierno sino también un cuerpo de leyes racionales escritas debían disponerse, consecuentemente, como expresión de la voluntad del pueblo. A esta concepción añadió, por otro lado, una justificación de la apropiación privada derivada de un derecho individual de preservación que, a su vez, se correspondía con el deber de "preservación de toda la Humanidad". Ambas justificaciones pueden verse conjuntamente, como propone Jordi Mundó, como una concepción fiduciaria de la libertad política (Mundó, 2017, 447).

Puntualicemos algo que tal vez pueda pasar desapercibido: el deber de preservar la existencia de la humanidad, incluyendo su patrimonio común, se refiere a individuos y pueblos en cualidad de fideicomitentes en beneficio de un tercero, la humanidad. Esto requeriría una serie de instituciones civiles y políticas que aplicaran en su diseño un principio fiduciario. Lo que tratamos de resaltar es que, a diferencia del beneficiario, la figura del fideicomitente no es pasiva, implica una forma de agencia por cuanto debe orientar y llevar a cabo un curso de acción con importantes restricciones informativas. Vistas así las cosas, traer el esquema

6 Como al propio Marx le gustaba recordar, todavía en el siglo XVI Thomas Müntzer se inspiró en esa consigna para denunciar un hecho intolerable: "que se haya convertido en propiedad a todas las criaturas, a los peces en el agua, a los pájaros en el aire y a las plantas en la tierra, pues también la criatura debe ser libre" (Marx, 2004, 48). 
fiduciario a esta cuestión se presenta como un ejercicio analítico sumamente arriesgado: ¿En qué sentido pueden establecerse relaciones de confianza, condiciones para la rendición de cuentas y la revocabilidad de esas relaciones, en interés de la humanidad? ¿Qué faculta a estos agentes para la inteligibilidad y la consecución de estos deberes? ¿En qué medida puede concebirse ese deber como un acuerdo humano? Este tipo de problemas filosóficomorales fueron mal que bien sorteados lidiando con la figura de Dios. Pero como señalamos anteriormente, introducir la noción de derechos subjetivos al derecho natural invitaba a reconocer en las facultades morales de los individuos algún rastro de sus propias experiencias.

También sobre estas cuestiones Locke puso su granito de arena con la idea del "sentido común", pero, nuevamente, hasta finales del siglo XVIII y principios del XIX no hubo una teorización suficientemente clara sobre el hecho de que las facultades morales humanas se conforman en el seno de la vida social. No cabe ninguna duda de que Marx quedó fuertemente persuadido con esta idea y que, como veremos, procuró integrarla en sus desarrollos teóricos hasta las últimas consecuencias.

La irrupción de la Revolución Francesa, y muy particularmente el período entre 1793 y 1794, fue un episodio culminante del iusnaturalismo revolucionario defendido, impulsado y protagonizado por el movimiento democrático de las comunidades campesinas (Gauthier, 2014). Sus logros y, sobre todo, las consecuencias políticas y económicas de su derrota, dejaron una huella en prácticamente todos los movimientos revolucionarios posteriores. En los albores de la revolución existía en Francia todo un cuerpo de conceptos y principios, un sentido común, compartido por el grueso de las clases populares. El programa político que se desprendía de este sentido común estaba encabezado por la universalización del derecho a la existencia, la soberanía popular y la erradicación de formas de dependencia en todos los ámbitos de la vida social (Domènech, 2004).

\section{Marx y la tradición iusnaturalista}

Las constantes alusiones de Marx, en su juventud, a un plano normativo superior de cualidades humanas se ha interpretado ya como una mirada utópica hacia un futuro lejano, ya como un proceso por el que trataba de despegarse, todavía sin lograrlo, de ataduras metafísicas hegelianas. Si bien es cierto que en la mayoría de sus alusiones a los derechos naturales Marx se mostró renuente a dar por buena toda idea filosófico-política pretérita, el iusnaturalismo como disciplina, mal que pesara a muchos, había quedado relegado en poco tiempo al museo de doctrinas muertas. Trató, en todo caso, de ir al fondo de la cuestión en aquello que le parecía cobrar relevancia histórica y política en el presente. Recurrió, también, a un esquema (o varios) de desarrollo histórico gravemente problemático que él mismo abandonó al final de su vida ${ }^{7}$. En este apartado sostendremos que, a pesar de todo eso, ni

7 “[...] acontecimientos asombrosamente análogos pero que se dan en ambientes históricos diferentes llevan a resultados totalmente diferentes. Estudiando cada una de estas formas de evolución por separado y luego comparándolas podrá acaso descubrirse fácilmente la clave del fenómeno, pero nunca se llegará a eso mediante el pasaporte universal de una teoría general histórico-filosófica, la virtud suprema de la cual consiste en ser suprahistórica." Carta de Marx en 1877 al director del periódico Otyecestvenniye Zapisky. (Versión en inglés: Marx y Engels, 2010, 200). Traducido en: Domènech (2009). 
se entregó a especulaciones idealistas en sus textos juveniles ${ }^{8}$ ni abandonó en su madurez un núcleo de preocupaciones antropo-filosóficas y políticas herederas de la vertiente iusnaturalista revolucionaria. Conscientes de que esta posición ha sido defendida por reputados autores como Ernst Bloch (1980 [1961]), György Lukács (1970 [1938]) o Eugene Kamenka (1972), trataremos de ofrecer en esta ocasión un breve repaso en cuestiones que creemos pueden servir al debate en el marco de la discusión actual en torno a la tradición republicana.

Una interpretación predominante, sin embargo, encorsetó las impugnaciones de Marx en una narración condescendiente con las inclinaciones democráticas que permanecían, de hecho, en el imaginario de las clases populares. La mordaz ironía con la que Marx quiso desalentar a los nuevos portavoces del lenguaje de derechos naturales y el "nebuloso cielo azul de la ideología republicana" contribuyó a que al final de su vida se comenzara a considerar su propia obra como una teoría sin arranque normativo. $\mathrm{O}$, si es que puede considerarse como tal, una teoría cuyo único arranque fuera el supuesto deber de aprovechar oportunamente la ocasión para acelerar un proceso histórico predestinado hacia el socialismo. Bajo esta interpretación, leer los textos de Marx traería consigo una triste paradoja: la inflexible y apasionada defensa de derechos fundamentales como la libertad de expresión o la libertad de asociación se podrían juzgar eventualmente como inoportunos para la marcha revolucionaria de la clase trabajadora. Llevando al extremo esta paradoja, podría aducirse bajo esa trágica desaprensión que los pasajes en los que Marx defiende derechos supuestamente "burgueses" deben entenderse como el alegato de alguien que simplemente cumple la misión de su tiempo. Pero la ciencia social normativa actual dispone de una serie de exigencias por las que una afirmación semejante difícilmente puede salir al paso.

En su etapa universitaria Marx trató de resolver tensiones conceptuales en torno a la relación entre hechos y normas. En desacuerdo con la tendencia conservadora de la mayoría de sus profesores, cercanos a la Escuela Histórica del Derecho, forjó una actitud displicente hacia el estudio arqueológico del derecho romano como técnica jurisprudente. Este fue el contexto en el que se aproximó a la obra de Hegel y al círculo intelectual de sus discípulos, firmes opositores a los principios antilustrados del absolutismo y a las reformas monárquicas que se pretendían llevar a cabo. El principal exponente de la Escuela Histórica, Friedrich von Savigny, popularizó una concepción del derecho opuesta al iusnaturalismo y abiertamente antirrepublicana. La verdadera fuente del derecho, según Savigny, era ajena a cualquier fórmula racionalista y se asentaba en la fuerza de los hechos, cuya interpretación quedaba bajo custodia de una técnica jurídica que el pueblo llano no podría llegar a comprender. Entre las numerosas invectivas dirigidas contra esta corriente, Marx dedicó uno de sus artículos periodísticos más beligerantes a El manifiesto filosófico de la Escuela Histórica del Derecho (1842). Savigny había sido nombrado como "alto canciller" para dirigir un plan de reformas, así que la opción escogida para evitar la censura fue desarmar el contenido del antecesor directo de esta escuela, Gustav Hugo.

8 En este sentido, Miguel Abensour sugirió, en su renovador estudio sobre los escritos de Marx de 1843, que antes de esa fecha podía reconocerse al joven renano una noción"absoluta" del Estado basada en la "autonomía de lo político" (Abensour, 1998).

9 Artículo de 1848 para el periódico Neue Rheinische Zeitung: "The Paris Reforme on the Situation in France". Traducción propia de: Marx y Engels $(1972,142)$. 
El análisis crítico de las sucesivas reformas presenta una y otra vez el mismo molde: un compromiso anclado en principios universalistas de verdad y dignidad humana; en sentido positivo, describiendo los hechos en correspondencia con la realidad objetiva, y en un sentido normativo, bajo un escrutinio centrado en el libre despliegue de potencialidades humanas. Pero cabría añadir otro importante desideratum adoptado: la verdad contenida en un planteamiento moral no se agota en su formulación, debe gozar también de una adhesión por parte de agentes que estén dispuestos a guiar su acción de acuerdo con este planteamiento en el contexto en el que viven. La capacidad de estos agentes para llevar a cabo un curso de acción transformadora de acuerdo con principios universales es entendida por Marx como una fuerza social en sí misma. Este tipo de razonamientos, planteados de diferentes formas en sus escritos filosófico-políticos, raramente los acomoda en términos histórico-deterministas sino todo lo contrario: los dispone a una tarea teórico-práctica en torno a las condiciones de posibilidad. Esa tarea consistía en promover principios racionalistas atendiendo el curso de contingencias históricas en la vida social y sus dinámicas de conflicto.

En los comentarios contra la ley sobre el robo de leña insistía favorablemente en un código legal como "esfera positiva de acción" que "elevará su propia clase [la de los pobres] a una posibilidad real de derechos" (Marx, 1983, 216). Además de compartir la matriz antropo-filosófica de la tradición iusnaturalista más radical -el carácter social, racional y no-instrumental de la naturaleza humana-, Marx mantiene intacta la necesidad de unas normas constitutivas que faculten la "libre individualidad". Para ello defiende que en cualquier diseño republicano coherente con principios universales la definición de la propiedad, como la de otros derechos civiles y políticos, no puede quedar circunscrita a la voluntad general del conjunto de ciudadanos en una comunidad si no se compadece con el bien de la humanidad.

Precisamente a estas incursiones en su región se referirá años más tarde como su iniciación a la crítica de la economía política ${ }^{10}$. Así empezaba a asomarse una crítica sobre la transformación de la definición legal "monopolista" de propiedad que promovían los legisladores. En esta seminal incursión a las formas de propiedad y sus particularidades históricas, tema que le obsesionó en diferentes momentos cruciales de su vida, trató de diseccionar con herramientas más propias de un jurista clásico a) la naturaleza del objeto de propiedad, la relación entre personas y cosas, y b) una evaluación normativa de estas relaciones en correspondencia con el modo de existencia de los individuos en su contexto social y político determinado.

En esta serie de artículos sobre la penalización del robo de leña denunciaba frontalmente la "unilateralidad" con la que se reconocían como positivas las costumbres que favorecían a los privilegiados ${ }^{11}$, reclamando para los desposeídos, cuyos derechos fueron progresivamente enajenados, el derecho inalienable a una existencia social autónoma.

10 "Aunque el objeto de mis estudios especializados fue la jurisprudencia, la consideraba sólo como una disciplina subordinada al lado de la filosofía y la historia. En 1842-1843, siendo director de la Rheinische Zeitung, me vi por primera vez en la embarazosa obligación de pronunciarme sobre lo que se llaman intereses materiales". Prólogo a la Contribución a la crítica de la economía política (Marx 1989, 6).

11 "Los derechos consuetudinarios nobiliarios se oponen por su contenido a la forma de la ley general. No pueden ser transformados en leyes porque han sido formados por la falta de leyes" (Marx, 1983, 212). 
Nosotros, en cambio, hombres poco prácticos, reclamamos para la multitud políticamente pobre y socialmente desposeída, aquello que la servidumbre erudita y dócil de los llamados históricos ha descubierto a modo de piedra filosofal para transformar en oro jurídico toda pretensión ilícita. Reivindicamos para la pobreza el derecho consuetudinario, un derecho consuetudinario que no es local sino que pertenece a los pobres de todos los países. Vamos aún más lejos y afirmamos que el derecho consuetudinario, por su naturaleza, sólo puede ser el derecho de esta masa inferior, desposeída y elemental. Lo que se entiende por las llamadas costumbres de los privilegiados son costumbres contra el derecho (Marx, 1983, 210).

De este modo se alineaba con la tradición democrática fraternal basada en el derecho escrito, una legislación racional ${ }^{12}$ congruente con las costumbres de la gente común. La continuidad con la "economía política popular" robespierriana quedaba expresada de modo inconfundible.

En estas costumbres de la clase pobre vive pues un sentido jurídico instintivo, su raíz es positiva y legítima y la forma del derecho consuetudinario es tanto más adecuada cuanto la existencia de la propia clase pobre es hasta ahora una mera costumbre de la sociedad civil que no ha encontrado aún un lugar adecuado dentro de la estructuración consciente del estado (Marx, 1983, 215).

\section{La Revolución francesa, la sociedad burguesa y el socialismo}

La disparidad de valoraciones en la obra de Marx y Engels en torno al curso de sucesos de la Revolución francesa sugiere que el estudio de esta - un proceso ininterrumpido y minucioso pero errático que puede trazarse desde el estudio de fuentes documentales en los cuadernos de Kreuznach (1843), Paris (1844), Bruselas (1845) y Manchester (1845-1847) hasta las referencias citadas en la Crítica al programa de Erfurt (1891) ${ }^{13}$ - sirvió primordialmente como un laboratorio de ideas. En su primer ajuste de cuentas con la filosofía del derecho de Hegel prácticamente todas las cuestiones centrales aparecen directa o indirectamente vinculadas con las implicaciones de la Revolución francesa. Inmediatamente después comprendió que los jóvenes seguidores de izquierda mantenían una visión distorsionada de esta experiencia histórica y, por encima de todo, que no atendían las consecuencias políticas y socioeconómicas de la derrota del movimiento democrático fraternal. Por la misma razón, su invocación a los derechos naturales no encontraba un escenario propicio. El escenario real requería una agenda de "emancipación" que fuera más allá de prefiguraciones políticas. Se alejó así de la pretensión de dar respuesta teórico-política al anhelo revolucionario y pasó a ponerlo en el cauce de un desarrollo histórico. En 1880 defendería todavía el propósito de "preparar el camino para un socialismo crítico y materialista, que en sí mismo pueda reflejar de modo inteligible el desarrollo histórico real de la producción social"14.

12 En este sentido, en otro artículo de la misma época vio la necesidad de enfatizar que "un código de leyes es la Biblia de la libertad de un pueblo" (Marx, 1983, 82).

13 Ver en Bruhat (1966) una indexación de todas estas fuentes.

14 Traducido de Marx y Engels (2010, 326-327); citado en Krätke (2018, 2). 
A través del estudio de la Revolución francesa integró en su esquema de desarrollo histórico una concepción de lucha de clases en el marco de una disputa por el poder político. La idea de un avance histórico promovido por la lucha de clases era un lugar común desde saintsimonistas hasta liberales doctrinarios, quienes reclamaban para el tercer estado el triunfo final del progreso humano ${ }^{15}$. Esta especie de profecía autocumplida impresionó a Marx y contribuyó decisivamente a que empezara a conformar un totum revolutum en su aproximación teórica sobre procesos sociales.

Poco antes de emigrar a París planeaba escribir una historia de la Convención (Krätke, 2018 , 7). Pretendía mostrar que la llegada icónica del Estado moderno no era sino una supeditación de las instituciones políticas a los intereses de una clase que impedía la plena consecución de los principios con los que trataba de legitimarse. Marx entendió el desenlace de la Revolución Francesa como la consolidación de la "sociedad burguesa", una coyuntura en la que los fundamentos republicanos se veían invertidos: las leyes burguesas no partían de premisas iusnaturalistas sino de su concepción de la propiedad. La "dictadura revolucionaria de los comités"16, fiscalizada por las comunas - de la que Marx pudo tomar buena nota leyendo el testimonio de Babeuf a través de Buonarroti o de las memorias del convencionalista Levasseur ${ }^{17}$-encontraba su opuesto en la dictadura militar: el poder político no era reapropiado por el pueblo sino que se disolvía en un ente, el Estado, que se sostenía como un fin en sí mismo ${ }^{18}$. Habiendo denunciado repetidamente que la defensa de derechos humanos debía corresponder a las condiciones objetivas, en la sociedad civil burguesa no podían sino ser invocados sesgada o "unilateralmente":

En el mundo moderno, todo individuo forma a la vez parte del sistema esclavista. Pero la esclavitud de la sociedad burguesa es, en apariencia, la mayor libertad, puesto que es, en apariencia, la independencia terminada del individuo, para quien el movimiento desenfrenado -liberado de las trabas generales y de las limitaciones impuestas por el hombre, de los elementos vitales de los que se le despojó, la propiedad, por ejemplo, la industria, la religión, etc., es la manifestación de su propia libertad, mientras que en realidad no es más que la expresión de su servidumbre absoluta y de la pérdida de su carácter humano. Aquí, el privilegio ha sido reemplazado por el derecho (Marx y Engels, 1981 [1844], 133).

15 "Por lo que a mí se refiere, no me cabe el mérito de haber descubierto la existencia de las clases en la sociedad moderna ni la lucha entre ellas. Mucho antes que yo, algunos historiadores burgueses habían expuesto ya el desarrollo histórico de esta lucha de clases y algunos economistas burgueses la anatomía económica de estas." "Carta a Joseph Weydemeyer, 5 de marzo de 1852", Marx (1976a, 453).

16 Por dictadura se entendía entonces una institución republicana, en un sentido cercano a su origen romano, pero en el marco de una república democrática. Los comités debían, en un período determinado de conflicto civil, llevar a cabo el mandato popular y rendir cuentas a sus mandatarios.

17 "La efervescencia popular había sido impulsada a un nivel lo suficientemente alto para que las clases sociales más elevadas empezasen a alarmarse... Había, de algún modo, una especie de guerra sorda, organizada entre el rico y el pobre" (traducción propia de Levasseur, 1989 [1830]).

18 "Está absolutamente fuera de duda que nuestro partido y la clase obrera sólo pueden llegar a la dominación bajo la forma de la república democrática. Esta última es incluso la forma específica de la dictadura del proletariado, como lo ha mostrado ya la Gran Revolución francesa". Así de tajante se mostró en su crítica al programa de Erfurt el viejo Engels (1891). 
Los nuevos códigos civiles de Francia y de todos los territorios conquistados por el Imperio Napoleónico supusieron una radical discontinuidad con el núcleo republicano: se pasó a reconocer derechos civiles a toda la población sin que hubiera correspondencia por activa o por pasiva con las condiciones de independencia material. Todo esto representaba para él el triunfo político de una clase en base a formas de dominación, "la forma moderna de esclavitud", fruto de unas transformaciones económicas irreversibles. Estas transformaciones fueron las que dieron lugar a las principales bases jurídicas constitutivas de esa sociedad burguesa: 1) el reconocimiento de unos derechos de propiedad privada absoluta; 2) el reconocimiento de un tipo de contrato de trabajo asalariado por el que el sujeto es formalmente libre de vender su fuerza de trabajo pero, a la vez, no tiene otra opción que alienar sus derechos en el ámbito de las relaciones de producción, y 3) la generalización de una estructura de intercambio generalizado que reducía todas las relaciones de reciprocidad a transacciones monetarias entre intereses individuales.

\section{Revisión de los fundamentos iusrepublicanos de la economía política ante el pro- greso industrial}

La crítica de la economía política de Marx contiene de forma disgregada una amplia y profunda revisión de las implicaciones de la matriz lockeana en la sociedad burguesa. Esto ha llevado a autores como Ronald L. Meek a sostener que no solo El Capital, sino que también Adam Smith y David Ricardo parten de un distanciamiento con la teoría de la propiedad de Locke (Meek, 1956, p.126). La gran historiadora marxista Ellen Meiksins Wood llegó incluso a afirmar que Locke sería el principal ideólogo de las bases teóricas que justificarían las características más esenciales de la dinámica capitalista ${ }^{19}$. La lista de autores que han seguido líneas similares sería muy larga, pero nos sorprende particularmente el caso de estos dos autores, cuyos argumentos son sumamente refinados y están bien informados, pero que apenas han recibido objeciones. Difícilmente podemos exponer en este artículo un análisis pormenorizado de estos argumentos, ni pretendemos dar a entender que deban ser enteramente rechazados. Existen importantes tensiones conceptuales en Locke, y algunas de estas tensiones estallaron con la industrialización. Marx, en efecto, avanzó en el terreno de la teoría y el análisis empírico desgranándolas. Pero si se soslayan los fundamentos iusnaturalistas en los razonamientos de Locke -no como inventor, sino como seguidor de esta tradición-, difícilmente pueda comprenderse cabalmente: 1) hasta qué punto las justificaciones de la acumulación capitalista y de un derecho absoluto a la propiedad privada son fruto de una tergiversación de las ideas de Locke (incluso aquellas ideas que, en su sentido original, con razón podrían verse muy alejadas del socialismo), y 2) hasta qué punto el sustrato normativo en la obra de Marx no es un mero ejercicio particularista de revisión de ideas contemporáneas. Queremos mostrar, por lo tanto, que hay una continuidad en el pensamiento de Marx con el núcleo normativo del que partió Locke en su concepción fiduciaria de la libertad republicana, y que vio en lo que llamaba las "contradicciones de la sociedad burguesa" la pertinencia teórico-práctica de revisarlo, volverlo inteligible y realizable.

19 Aunque insistió en la misma idea en otras publicaciones, la mayoría de sus argumentos están contenidos en su célebre libro sobre el origen del capitalismo (Wood, 2002). 
En primer lugar, Marx no rechazó la justificación filosófica según la cual es legítimo apropiarse de un instrumento al combinarse con el propio trabajo. Esta premisa lockeana vinculaba el derecho natural de preservación individual con la posesión común originaria. La premisa de partida no es aquí un problema de igualdad o desigualdad de recursos entre individuos, sino un problema sobre en qué medida es legítimo intervenir en la naturaleza. Esa medida es la capacidad del ser humano para producir su propia existencia, no un criterio meritocrático sobre el reparto del producto social. Recordemos que, para Locke, los seres humanos tenían también el deber de preservar el patrimonio de la humanidad. Por esa razón añadió que no era legítimo apropiarse de algo de lo que no podía sacarse valor de uso, y que en caso de hacerlo debía dejarse "tanto y tan bueno" para otros (Locke, 1988, II §33.). El famoso argumento de "la mejora" (improvement), según el cual Locke legitimaría la concentración de tierras y la explotación humana en base a la ventaja comparativa de quien sacara mejor provecho, no era en ningún caso un principio antecedente. La justificación meritocrática sobre la desigual apropiación de recursos naturales en función de las ventajas comparativas para sacar provecho de ellas, solo tiene un carácter derivado para Locke: garantizar la libertad y distribuir meritocráticamente el producto social eran dos planos normativos distintos.

Marx observó que en la sociedad burguesa imperaba un "materialismo abyecto" que distaba de esta concepción fiduciaria humanista, y que en este aspecto la matriz lockeana no podía servir de ningún modo de justificación, pues lo que antecedía a la propiedad burguesa era una dinámica de desposesión masiva. Con Locke y con el grueso de la tradición republicana, Marx remarcó insistentemente que la concentración en pocas manos de todos los recursos productivos hacía imposible cualquier forma de diseño que garantizara la libertad de los seres humanos. Solo fingiendo que el escenario de partida fuera otro podía considerarse a un capitalista algo así como un agente fiduciario a quien se le encargara guiar la producción de riqueza. La concentración de recursos productivos había llegado a tal punto que no era posible sostener que el enriquecimiento de unos pocos diera garantías para ningún tipo de diseño republicano que no partiera de una radical transformación de las relaciones de propiedad. Y aunque se aceptara esta ficción, cabía denunciar que el capitalista en realidad tenía un comportamiento tan impunemente parasitario como el de un señor feudal ${ }^{20}$.

La justificación lockeana de la apropiación podía aplicarse al acceso y al control de recursos siempre y cuando se basara en el trabajo personal. Pero esta afirmación entrañaba una profunda tensión, pues no aportaba una resolución definitiva sobre todos aquellos individuos que vivían o trabajaban en situación de dependencia ${ }^{21}$. Al reconocerse derechos de ciudadanía a individuos que se insertaban en relaciones de dependencia como único modo para subsistir, las relaciones de propiedad no podían entenderse sobre la base del trabajo personal:

20 "Estos son los trustees de la sociedad burguesa, pero se quedan en el bolsillo todo lo que procede de esta relación fiduciaria (Trusteeschaft)." Capital vol. III cap. 15 (Marx, 1981 [1894], 375). Trad. propia al castellano.

21 Locke era perfectamente consciente de que el trabajo asalariado era una forma de ilibertad. Scott G. Swanson sugiere, en contra de la opinión de muchos autores que interpretan un puro desdén aporofóbico por parte de Locke, que su omisión de protesta ante la situación de los trabajadores pobres (industrious poor) se debe a la ausencia de formas de erradicar las condiciones que daban lugar a esa pobreza (Swanson 1997, 453-454.). 
$\mathrm{Al}$ principio el derecho de propiedad se nos presentaba fundado en trabajo propio. Por lo menos, había que admitir ese supuesto, porque los únicos que se enfrentan son poseedores de mercancías con los mismos derechos, y el medio de apropiarse de la mercancía ajena es sólo la enajenación de la mercancía propia, y esta última no se puede producir sino mediante trabajo. La propiedad resulta ahora, por el lado del capitalista, el derecho de apropiarse de trabajo ajeno no pagado o de su producto, y, por el lado del trabajador, la imposibilidad de apropiarse de su propio producto. La separación de propiedad y trabajo se convierte en consecuencia necesaria de una ley que aparentemente partía de su identidad.” El Capital I, cap. XXII (Marx, 1976b, 225-226).

Por lo tanto esta dinámica expropiatoria vino acompañada de nuevas relaciones en el proceso productivo, basado en una particular combinación de fuerza de trabajo y medios de producción, que volvía ininteligible cualquier criterio distributivo sobre los frutos del trabajo. La transformación de la estructura de la propiedad a la que la industrialización daba lugar conllevaba que las justificaciones iusnaturalistas no podían ser incardinadas. Para ello se requería suponer de partida una asociación republicana entre individuos dentro del proceso productivo, una cooperación en condiciones de libertad recíproca. La desigualdad político-jurídica existente revelaba que no había medida posible de "valor"22 sobre la que se pudiera armonizar un diseño republicano con arreglo a una justicia distributiva. El concepto de "valor" en Marx no tenía este propósito, sino el de reflejar el curso real de la acumulación capitalista haciéndolo inteligible para un programa socialista basado en la apropiación en común de los medios de producción:

Esta expropiación se consuma mediante el funcionamiento de las leyes inmanentes de la producción capitalista misma, mediante la centralización de los capitales. [...] Junto con esa centralización, o expropiación de muchos capitalistas por pocos, se desarrolla la forma cooperativa del proceso de trabajo a escala constantemente creciente, la consciente aplicación técnica de la ciencia, la explotación planificada de la tierra, la conversión de los medios de trabajo en medios de trabajo sólo utilizables conjuntamente, la economización de todos los medios de producción mediante su uso como medios de producción de un trabajo social, combinado, el entrelazamiento de todos los pueblos en la red del mercado mundial, y, con ello, el carácter internacional del régimen capitalista. [...][A] umenta la masa de la miseria, de la opresión, de la servidumbre, de la degeneración, de la explotación, pero también la indignación de la clase obrera en constante crecimiento y educada, unificada y organizada por el mecanismo del proceso de producción capitalista. El monopolio del capital se convierte en traba del modo de producción que ha florecido con él y bajo él. La centralización de los medios de producción y la socialización del trabajo alcanzan un punto en el cual se hacen incompatibles con su cobertura capitalista. Suena la hora de la propiedad privada capitalista. Los expropiadores son expropiados. El Capital I, cap. XXIV (Marx, 1976b, 409).

22 Por eso, dice Marx, Aristóteles, quien al parecer no consideraba a todos los seres humanos como iguales -podríamos añadir, presumiblemente a su pesar, tampoco Locke-, no podía concebir la métrica de valor: "El enigma de la expresión de valor [...] no se puede descifrar hasta que el concepto de la igualdad humana adquiere ya la firmeza de un prejuicio popular" (Marx, 1976b, 69). 


\section{Economía política del trabajo, el triunfo de un principio}

Según Marx, aquellas facultades morales de raíz "positiva y legítima" que acabaron adquiriendo "la firmeza de un prejuicio popular" para poder "descifrar" el "secreto de la expresión del valor" eran el principio de igualdad humana. Pero en la sociedad burguesa esa igualdad se veía reducida a una mera equivalencia en el intercambio de mercancías entre sus poseedores. Este paso habilitó una ruptura decisiva con la premisa teórica de los autores predecesores de la Economía Política, desde los escolásticos a Smith y Ricardo, sobre los precios "justos" o "naturales" en torno a los cuales gravitarían los salarios. Marx mostró que el secreto de la acumulación se originaba en una relación de dominación entre capitalistas y trabajadores. El propietario de los medios de producción ejercía arbitrariamente su autoridad, tratando instrumentalmente al trabajador, a fin de maximizar la diferencia entre el valor de cambio de aquello producido y el valor de cambio de la fuerza de trabajo. Pero entonces, ¿qué determinaba el valor de la fuerza de trabajo?

Con un propósito analítico, Marx se empecinó en tratar de cerrar un modelo en el que pudiera reflejarse la equivalencia del agregado de horas de trabajo con "una suma determinada de medios de vida" (Marx, 1976b, 187) en un momento concreto. Sin embargo esa equivalencia no podía ser determinada sin tener en cuenta un "elemento histórico y moral" (Marx, 1976b, 186), ya que no podía naturalizarse objetivamente en una cantidad necesaria. La clase de los trabajadores, podría decirse, gozan de un nivel promedio de condiciones de vida, y solo gracias a sus facultades morales puede cada uno de sus miembros juzgar de qué modo se ajusta a una "suma" mínimamente aceptable. Esta circunstancia se daba antaño en disputas en torno a los precios y el acceso directo a medios de subsistencia, y se daba también en torno al aumento de la productividad con el paso a la industrialización.

Esas facultades morales emergían hasta el punto en que los trabajadores podían tomar conciencia, podían reclamar colectivamente una mayor proporción de la riqueza producida, ya fuera a través de la negociación o de la consecución de un marco de garantías legales. Esa dimensión ética del comportamiento humano, que en su momento fuera la premisa antropo-filosófica del concepto de fraternidad, era precisamente de lo que carecían las teorías utilitaristas que iban ganando popularidad. Pero ahí no acababa todo, pues podían tomar conciencia de un conjunto de condiciones de posibilidad más allá de la disputa salarial o de cualquier tipo de mal arreglo redistributivo. Al fin y al cabo, el aumento salarial en términos absolutos podía dejar intacta la dinámica de acumulación capitalista. Si bien la disputa en torno a la productividad articulaba críticamente el conflicto de clase creando medios organizativos -de una clase "educada, unificada y organizada"-, Marx entendía que era perfectamente natural esperar que los trabajadores, en algún momento, aspirasen fraternalmente a conseguir una existencia social autónoma.

Con esto en mente, Marx celebró en su discurso inaugural de la Asociación Internacional de Trabajadores (1864) ${ }^{23}$ el "triunfo de un principio", la nueva legislación inglesa conocida como Ten Hours Bill, que prohibía la extensión de la jornada laboral más allá de las 10

23 Las citas siguientes pertenecen al "Manifiesto Inaugural de la Asociación Internacional de los Trabajadores" pronunciado por Marx en Londres en 1864. En Domènech (2004, 123 y ss.) puede leerse un extenso análisis, con traducción alternativa del autor, a quien debemos en buena parte la argumentación presentada en este texto. 
horas: "por primera vez la Economía política de la burguesía había sido derrotada en pleno día por la Economía política de la clase obrera". Esta conquista obrera suponía la refutación política y teórica de lo que hasta entonces la burguesía consideraba un axioma económico basado en leyes naturales. La pluralidad de corrientes que se congregaban en esta nueva organización recomendaba una especial prudencia por parte de Marx, cualquier expresión que pudiera ser interpretada de un modo caprichoso o especulativo podía comprometer su empeño por confraternizar ${ }^{24}$ y aunar el movimiento obrero. Su eficacia retórica dependía en buena medida de traer a su favor la preeminencia de los hechos ante el imaginario de las trade unions, las nuevas y viejas comunidades de trabajo cooperativo, la proliferación de diarios y asociaciones que, todas ellas, conformaban una incipiente consciencia proletaria. Las experiencias de 1848 habían enseñado una dura lección para todas las aspiraciones socialistas. A pesar del debilitamiento de expectativas revolucionarias en la última década, el liderazgo burgués no había hecho florecer desde entonces más que la falsedad de sus propias promesas y proseguir con la fatalidad de un "febril industrialismo": pauperización, represión y exclusión de derechos civiles y políticos.

"Pero estaba reservado a la Economía política del trabajo el alcanzar un triunfo más completo todavía sobre la Economía política de la propiedad”. Marx ponía el énfasis en los movimientos cooperativos, no por la capacidad de movilización y confrontar intereses en el interior de las fábricas, sino por ofrecer una prueba fehaciente de las condiciones de posibilidad del programa socialista:

$[\mathrm{H}]$ an mostrado con hechos, no con simples argumentos, que la producción en gran escala y al nivel de las exigencias de la ciencia moderna, puede prescindir de la clase de los patronos, que utiliza el trabajo de la clase de las «manos»; han mostrado también que no es necesario a la producción que los instrumentos de trabajo estén monopolizados como instrumentos de dominación y de explotación contra el trabajador mismo; y han mostrado, por fin, que lo mismo que el trabajo esclavo, lo mismo que el trabajo siervo, el trabajo asalariado no es sino una forma transitoria inferior, destinada a desaparecer ante el trabajo asociado que cumple su tarea con gusto, entusiasmo y alegría (Marx, 1864).

\section{Referencias}

Abensour, M. (1998), La democracia contra el Estado, Buenos Aires: Ed. Colihue.

Bertomeu, M. J. (2017), “Pobreza y propiedad ¿cara y cruz de la misma moneda?”, Isegoría, 57, 477-504.

Bertomeu, M. J. (2018), "El concepto de solidaridad y su multiplicidad semántica. A la memoria de Antoni Domènech", Éndoxa, 41, 213-237.

Bloch, E., (1980) [1961], Derecho natural y dignidad humana, Madrid: Aguilar.

Bruhat, J. (1966), "La Révolution française et la formation de la pensée de Marx", en: Annales historiques de la Révolution française, Societé des Etudes Robespierristes, 125-170.

24 Bertomeu $(2018,226)$ ha puesto de relieve que el sentido en el que Marx usa el término "solidaridad" es, particularmente en este discurso de Marx, plenamente compatible con el de la fraternidad revolucionaria. 
Domènech, A. (1989), De la ética a la política, Barcelona: Crítica.

Domènech, A. (1993), “'Summum ius summa iniuria'. (De Marx al éthos antiguo y más allá)”, en: C. Thiebaut (ed.), La herencia ética de la ilustración, Barcelona: Crítica, 175-197.

Domènech, A. (2004), El eclipse de la fraternidad: una revisión republicana de la tradición socialista, Barcelona: Crítica.

Domènech, A. (2009), “¿Qué fue del marxismo analítico? (En la muerte de Gerald Cohen)”, Revista Sin Permiso, 6, 33-72.

Domènech, A., y Bertomeu, M. J. (2016), "Property, freedom and money: Modern Capitalism reassessed", European Journal of Social Theory, 19(2), 245-263.

Engels, F. (1891), "Contribución a la crítica del proyecto de programa socialdemocrata de 1891", en: https://www.marxists.org/espanol/m-e/1890s/1891 criti.htm (consultado el 2/5/2020).

Garnsey, P. (2007), Thinking about property: from antiquity to the age of revolution, Cambridge and New York: Cambridge University Press.

Gauthier F. (2014), Triomphe et mort de la Revolution des Droits de l'Homme et du Citoyen (1789-1795-1802), Paris: Syllepse.

Gourevitch, A. (2013), "Labor republicanism and the transformation of work", Political Theory, 41(4), 591-617.

Kamenka, E. (1972), Los fundamentos éticos del marxismo, Buenos Aires: Paidós.

Krätke, M. R. (2018), "Marx and world history", International Review of Social History, 63(1), 91-125.

Leipold, B. (2017), Citizen Marx: the relationship between Karl Marx and republicanism, tesis doctoral, University of Oxford.

Levasseur, R, (1989)[1830], Mémoires de R. Levasseur (de la Sarthe) Ex-Conventionnel, 1829-31, Paris: Messidor/Éditions Sociales.

Levine, N. (1987), "The German historical school of law and the origins of historical materialism", Journal of the History of Ideas, 48(3), 431-451.

Locke, J. (1988), Two Treatises of Government, ed. Peter Laslett, 2nd. ed., Cambridge: Cambridge University Press.

Lukács, G. (1970) [1938], El joven Hegel: y los problemas de la sociedad capitalista, trad. Manuel Sacristán, Barcelona: Grijalbo.

Marx, K. (1864), "Manifiesto Inaugural de la Asociación Internacional de los Trabajadores", en: https://www.marxists.org/espanol/m-e/1860s/1864fait.htm (consultado el 02/05/2020).

Marx, K. (1976a), Obras Escogidas en 2 tomos, Tomo II, Moscú: Ediciones Moscú.

Marx, K. (1976b), El Capital. Libro I, trad. de M. Sacristán, Barcelona: Ed. Grijalbo.

Marx, K. (1981) [1894], Capital: A Critique of Political Economy. Volume Three, trad. David Fernbach, Harmondsworth: Penguin.

Marx, K. (1983), En defensa de la libertad: los artículos de la Gaceta Renana, 1842-1843 (Vol. 6), Valencia: Fernando Torres.

Marx, K. (1989) [1857], Contribución a la crítica de la economía política, Moscú: Ed. Progreso.

Marx, K. (1997), Writings of the young Marx on philosophy and society, Massachussets: Hackett Publishing. 
Marx, K. (2004) [1844], Sobre la cuestión judía, Buenos Aires: Prometeo Libros Editorial.

Marx, K. y Engels, F. (1972), Articles from the Neue Rheinische Zeitung, Moscú: Ed. Progreso.

Marx, K. y Engels, F. (1981) [1844], La sagrada familia (2a ed.), Madrid: Akal.

Marx, K. y Engels, F. (2010), Marx \& Engels Collected Works vol. 24, Londres: Lawrence \& Wishart.

Meek, R. L. (1956), Studies in the Labour Theory of Value, 2nd. ed., Nueva York y Londres: Monthly Review Press.

Mundó, J. (2017), "La constitución fiduciaria de la libertad política. (Por qué son importantes las coyunturas interpretativas en la filosofía política)", Isegoría, 57, 433-454.

Roberts, W. C. (2016), Marx's inferno: The political theory of capital, Princeton, NJ: Princeton University Press.

Stedman Jones, G. (2017), Karl Marx: greatness and illusion, Boston: Harvard University Press.

Swanson, S. (1997), "The medieval foundations of John Lock's theory of natural rights: rights of subsistence and the principle of extreme necessity", History of Political Thought, 18 (3), 399-459.

Thompson, M.J. (2019), “The Radical Republican Structure of Marx’s Critique of Capitalist Society", Critique, 47(3), 391-409.

Tierney B. (2001), The Idea of Natural Rights, Michigan: Eerdmans Publishing Company. Wood, E. M. (2002), The origin of capitalism: A longer view, Nueva York: Verso. 